\title{
Naringin promotes cellular chemokine synthesis and potentiates mesenchymal stromal cell migration via the Ras signaling pathway
}

\author{
FENG LIN, YUAN ZHU and GANGFENG HU
}

\author{
Department of Orthopedics, Xiaoshan First People's Hospital, Hangzhou, Zhejiang 310000, P.R. China
}

Received September 24, 2017; Accepted July 13, 2018

DOI: $10.3892 /$ etm.2018.6634

\begin{abstract}
Directional migration of mesenchymal stem cells (MSCs) is known to serve roles in bone fracture healing. Naringin is a traditional medicine used in China to treat bone injury and has been confirmed to act as a chemoattractant to MSCs. In the present study, the secretion of chemokines and stimulation of relevant signaling pathways by naringin were detected to determine the molecular mechanism of naringin-induced MSC migration. In these experiments, Quantibody ${ }^{\circledR}$ arrays were used to detect chemokines secreted by MSCs with or without the addition of naringin. The results revealed differential naringin-induced chemokine secretion of C-X-C motif chemokine (CXCL)5, CXCL6 and C-C motif chemokine 20. Furthermore, the Ras signaling pathway was markedly activated in the naringin-treated groups, suggesting that naringin may enhance the migrational ability of MSCs via Ras activation. Furthermore, naringin was able to promote the secretion of various chemokines derived from MSCs, which would, in turn, increase the mobility of MSCs. The aim of the present study was to provide novel candidate agents for clinical orthopedics and theoretical basis for the future improvement of adjunctive medication for bone fracture healing.
\end{abstract}

\section{Introduction}

Naringin is a dihydroflavonoid compound with numerous biological and pharmacological roles, including anti-inflammatory, anticancer, antiulcer, analgesic and anti-hypertensive activities (1-4). Naringin exhibits estrogenic activity and can decrease blood cholesterol, reduce thrombus formation, and improve local microcirculation and nutritional supply (5-9). Therefore, naringin is widely used in clinical practice to prevent cardiovascular and cerebrovascular diseases and as

Correspondence to: Dr Gangfeng Hu, Department of Orthopedics, Xiaoshan First People's Hospital, 199 Shixin South Road, Hangzhou, Zhejiang 310000, P.R. China

E-mail: doctorhu_hz@163.com

Key words: naringin, mesenchymal stem cells, chemokine, Ras signal pathway an adjunctive treatment for bone fracture healing (10-13). A Previous study has indicated that naringin can promote bone marrow stem cell differentiation into mature bone. However, it inhibits differentiation of MSCs into adipocytes (14). Furthermore, naringin can inhibit bone loss and increase bone density (15).

Bone MSCs are adult multipotent cells derived from the fetal mesoderm that exhibit a high proliferation, self-renewal and differentiation potential (16-18). MSCs participate in bone fracture repair (19). Directional migration of MSCs and differentiation into mature bone serve essential roles in the local healing of bone fractures (20). Additionally, MSCs exhibit autocrine and paracrine functions and may secrete a number of cytokines, growth factors, chemokines and other regulators that participate in cellular functions (21). Therefore, differential secretion of various cytokines by MSCs under the effects of suitable medication can alter the microenvironment of MSCs in bone fractures as well as the traits and function of other associated cell types, thereby affecting bone fracture healing.

The Ras signaling pathway is a common molecular signal transduction pathway in cells. Binding of the receptor protein tyrosine kinase to signaling molecules forms a dimer and results in autophosphorylation and activation of the receptor protein tyrosine kinase and Ras (22). Activated Ras induces a protein kinase phosphorylation cascade $(23,24)$. Previous studies have shown that activation of the Ras signaling pathway is associated with the proliferation and migration of numerous cell types, including cancer cells $(18,25,26)$. A previous report by the authors of the present study indicated that activation of Ras-associated protein-1 promotes directional migration of MSCs (16). Therefore, the authors of the present study hypothesized that naringin may potentiate the migration of MSCs via the activation of Ras and this hypothesis was supported by the following experiments.

A scratch assay was used in the present study to preliminarily detect the effect of naringin on MSC migration. To confirm the hypothesis of the present study and further investigate the molecular mechanism of naringin on MSCs, Quantibody ${ }^{\circledR}$ arrays (RayBiotech, Inc., Norcross, GA, USA) were used to detect the cytokines secreted by MSCs. It was hypothesized that naringin may affect MSC cytokine secretion and that chemokine secretion by naringin-induced MSCs is the mechanism by which this drug promotes MSC migration. By analyzing the results of the Quantibody ${ }^{\circledR}$ array, differentially 
synthesized chemokines secreted by naringin-induced MSCs were identified. The Ras signaling pathway activity was selected as it associated with MSC migration. The aim of the present study was to provide novel candidate agents for clinical orthopedics and theoretical basis for the future improvement of adjunctive medication for bone fracture healing.

\section{Materials and methods}

Reagents. MSCs (cat. no. HUXMA-01001) and Human MSC basal culture medium (cat. no. HUXMA-9001c) were purchased from Cyagen Biosciences, Inc. (Santa Clara, CA, USA). Naringin (Fig. 1) at a purity $>95 \%$ (Sigma-Aldrich; Merck KGaA, Darmstadt, Germany) was dissolved in physiological saline, according to the manufacturer's protocol. Ras inhibitor (Selleck Chemicals, Houston, TX, USA), a transferase inhibitor of GTPase HRas and GTPase KRas, was used at a concentration of $5 \mu \mathrm{M}$.

Isolation and culture expansion of human bone marrow MSCs. Adherent MSCs were trypsinized and passaged when the cell confluence reached $\sim 80 \%$. Cells at passages 3-5 were used in the following experiments. Typically, these cells exhibited the capacity of differentiation into osteoblasts, adipoblasts and chondrocytes.

Transwell migration assay. Cell migration was carried out with Transwell chambers (pore size, $8-\mu \mathrm{m}$ diameter; Costar; Corning Incorporated, Corning, NY, USA). Human MSC basal culture medium was added into the wells of a 24-well plate and subsequently serum-starved MSCs $\left(1 \times 10^{5}\right)$ suspended in $100 \mu \mathrm{l}$ of complete medium containing $0.1 \%$ FCS were added into the upper chamber. Prior to the addition of naringin, the Transwell plate, with MSCs in the upper chamber and medium containing $0.1 \%$ FCS only in the lower chamber, was first incubated at $37^{\circ} \mathrm{C}$ for $1 \mathrm{~h}$. Following the addition of naringin (1.0 or $10 \mu \mathrm{M})$ and the inhibitor $(10 \mu \mathrm{M}$ naringin $+5 \mu \mathrm{M}$ inhibitor), the plate was incubated at $37^{\circ} \mathrm{C}$ for $3 \mathrm{~h}$, followed by membrane fixation with $4 \%$ paraformaldehyde and staining with $0.1 \%$ crystal violet at $25^{\circ} \mathrm{C}$ for $20 \mathrm{~min}$. The membrane was subsequently washed and the cells on the underside of the membrane were observed under a light microscope (magnification, $x 400$ ). Numbers of cells were counted in five to ten random fields of view for each membrane.

Cell scratch assay. Cell migration was determined using a scratch assay. The cells were cultivated to $90 \%$ confluence on 12 -well plates at $25^{\circ} \mathrm{C}$ and treated with naringin $(0.1,1.0$ and $10 \mu \mathrm{M}$ ), or controls (without naringin). In further experiments, MSCs were pretreated with $10 \mu \mathrm{M}$ naringin. Following $6 \mathrm{~h}$, the supernatant of the MSCs was extracted to culture a new batch of MSCs and a scratch assay was performed using a $1 \mathrm{ml}$ micropipettor to form the scratch. The MSCs were recorded at 0 and $6 \mathrm{~h}$. Subsequently, cell scrapers (Corning Incorporated) were utilized to scratch the confluent cells. The extent of cellular growth was observed at 0 and $6 \mathrm{~h}$. All experiments were repeated three times.

Western blotting. Cells were harvested and lysed in radioimmunoprecipitation assay buffer (Cyagen Biosciences, Inc.) supplemented with protease inhibitors. Protein concentrations were determined using a Novagen ${ }^{\circledR}$ Bicinchoninic Acid Protein Assay kit (Merck KGaA). Following determination of the concentration $(5.534 \mu \mathrm{g} / \mu \mathrm{l})$, protein samples $(60 \mu \mathrm{g})$ were separated by $10 \%$ SDS-PAGE and transferred to polyvinylidene difluoride membranes. Membranes were blocked in $5 \%$ skim milk for $1 \mathrm{~h}$ at $25^{\circ} \mathrm{C}$. And incubated with antibodies against guanosine-5'-triphosphate (GTP)-Ras (cat. no. 16117; 1:500; Active Ras Detection kit; Thermo Fisher Scientific, Inc., Waltham, MA, USA), Ras (cat. no. ab52939; 1:5,000; Abcam, Cambridge, UK), and $\beta$-actin (cat. no. dc-130301; 1:2,000; Santa Cruz Biotechnology, Inc., Dallas, TX, USA), overnight at $4^{\circ} \mathrm{C}$. Following incubation with horseradish peroxidase-conjugated goat anti-rabbit secondary antibodies (cat. no. 31210; 1:5,000; Thermo Fisher Scientific, Inc.), immunoreactive proteins were visualized using a Pierce ${ }^{\mathrm{TM}}$ Fast Western Blot kit, ECL Substrate (cat. no. 35055; Thermo Fisher Scientific, Inc.). Fluorescence intensity was measured using the ImageQuant ${ }^{\mathrm{TM}}$ LAS4000 system (GE Healthcare, Chicago, IL, USA; measurement parameter, high resolution). Relative quantification of the bands was performed using ImageJ software (version 5.0; National Institutes of Health, Bethesda, MA, USA).

Antibody array. Soluble proteins in the medium of the MSCs were measured using the Quantibody ${ }^{\circledR}$ Human Cytokine Array G1000 (RayBiotech, Inc.; cat. no. AAH-CYT-G1000), according to the manufacturer's protocol. Quantibody ${ }^{\circledR}$ arrays can detect 120 proteins. MSCs were plated 3 days prior to the experiment in Human MSC basal culture medium and were $75-90 \%$ confluent. The treatment group was stimulated with $10 \mu \mathrm{M}$ naringin and compared with the non-stimulated culture for 7 days. The cell lysis solution was collected and filtered. Medium was also hybridized to the arrays and subsequently used for normalization. A total of 10 technical and biological replicates were conducted and demonstrated a very high positive correlation (Pearson correlation coefficient $>0.9$; data not shown). Hybridization was conducted overnight at $4^{\circ} \mathrm{C}$. All slides were scanned using the ImageQuant ${ }^{\mathrm{TM}}$ LAS4000 system and analyzed using GenePix Pro 6.0 software (Molecular Devices, LLC, Sunnyvale, CA, USA). The median score was used and averaged across triplicates for each array. The results were subsequently normalized using internal controls and the values for cytokines in clear medium containing $10 \%$ FBS were subtracted.

Bioinformatics analysis. The analysis of cytokine-cytokine receptor interaction pathways were performed using the Kyoto Encyclopedia of Genes and Genomes database, (KEGG; https://www.kegg.jp/kegg/kegg2.html). The search function of the website was utilized to search for the cytokine-cytokine receptor interaction of CXCL5, CXCL6 and CCL20 for the species of Homo sapiens.

Statistical analysis. Analysis of variance and Student-Newman-Keuls test (one-way analysis of variance) were used for data analysis. Data were presented as the mean \pm standard deviation ( $\mathrm{n}=3$ for each experiment). $\mathrm{P}<0.05$ was considered to indicate a statistically significant difference. SPSS version 17.0 statistical software was utilized to analyze data (SPSS, Inc., Chicago, IL, USA). 

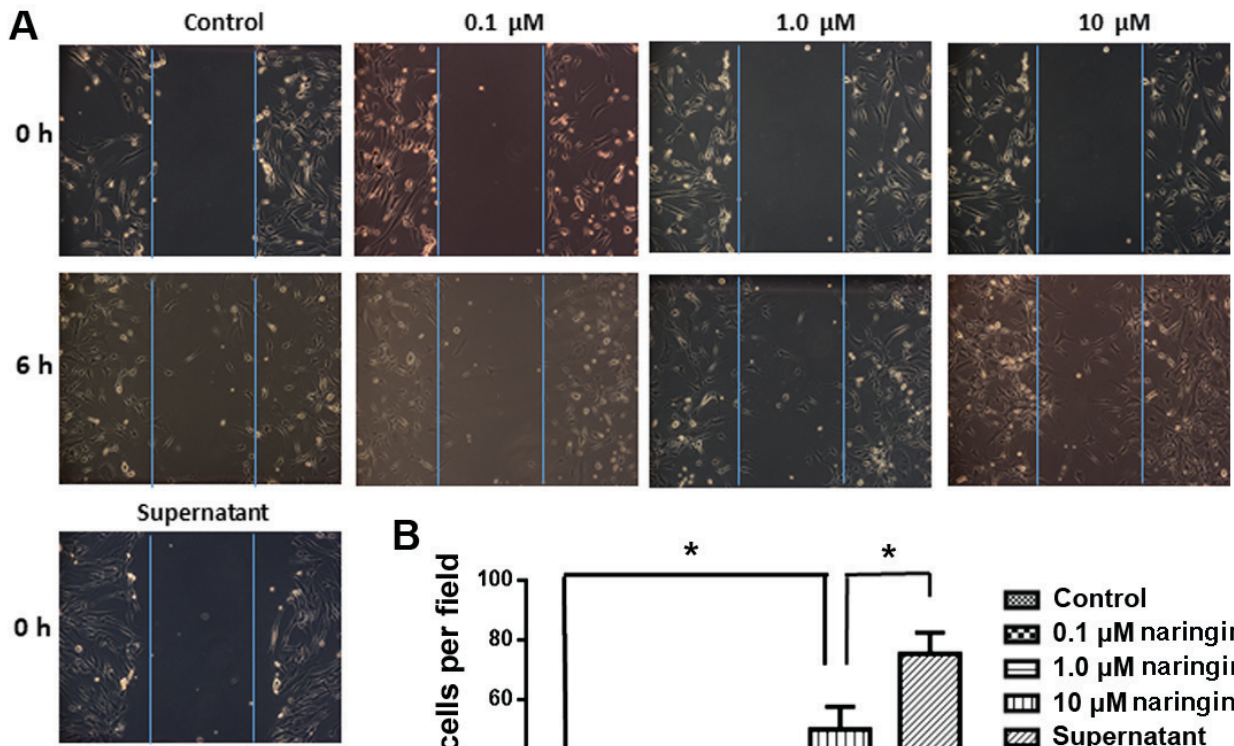

B

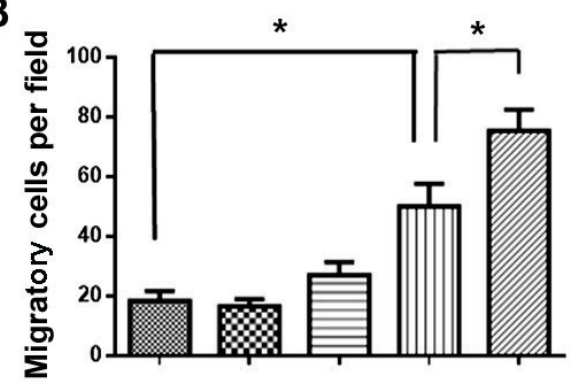

Control

$\mathbf{\infty} 0.1 \mu \mathrm{M}$ naringin

曰1.0 $\mu \mathrm{M}$ naringin

四 $10 \mu \mathrm{M}$ naringin

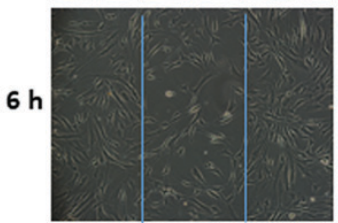

mapernatant

Figure 1. Naringin promotes the migration of MSC. (A) A scratch assay was conducted following treatment with different concentrations of naringin (0.1, 1.0 and $10 \mu \mathrm{M}$ ), supernatant or control. The MSCs are shown at 0 and $6 \mathrm{~h}$. Solid lines represent the baseline. (B) The migratory cells were counted and the results obtained from three independent experiments were presented as the mean \pm standard deviation ( $\mathrm{n}=3$ in each experiment). ${ }^{*} \mathrm{P}<0.05$. MSC, mesenchymal stromal cells.
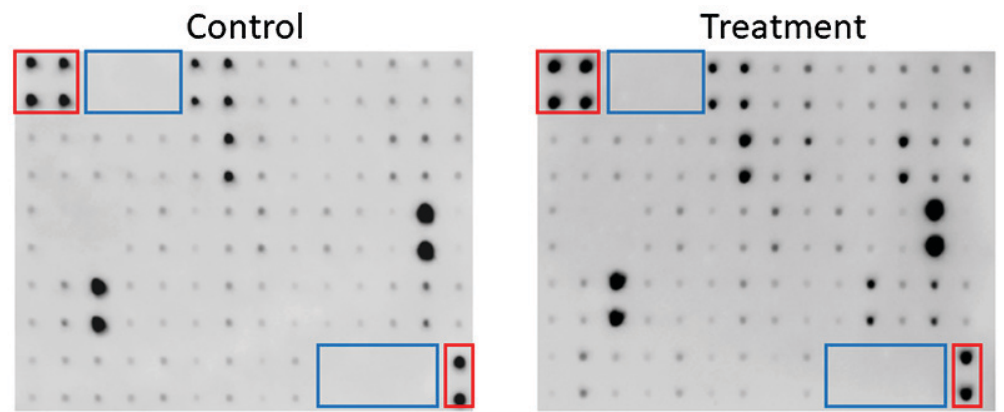

\begin{tabular}{|c|c|c|c|c|c|c|c|c|c|c|c|c|c|c|}
\hline & A & B & C & D & $E$ & $\mathbf{F}$ & G & H & I & J & $\mathrm{K}$ & L & M & $\mathbf{N}$ \\
\hline 1 & os & POS & NEG & NEG & NEG & ANG & BDNF & BLC & BMP-4 & AP-6 & $\begin{array}{c}\text { Ckß8- } \\
1\end{array}$ & CNTF & & \\
\hline 2 & POS & POS & NEG & NEG & NEG & ANG & BDNF & BLC & BMP-4 & BMP-6 & $\begin{array}{c}\text { Ckß8- } \\
1\end{array}$ & CNTF & CCL28 & $3 \mathrm{CCL} 1$ \\
\hline 3 & LL24 & CCL26 & FGF-6 & FGF-7 & $\begin{array}{l}\text { Flt-3 } \\
\text { Ligand }\end{array}$ & $\begin{array}{c}\begin{array}{c}\text { Fractal } \\
\text { kine }\end{array} \\
\end{array}$ & CXCL6 & GDNF & $\begin{array}{l}\text { GM- } \\
\text { CSF }\end{array}$ & 1-309 & IFN-Y & $\begin{array}{c}\text { IGFBP- } \\
1\end{array}$ & $\begin{array}{c}\text { IGFBP- } \\
2\end{array}$ & $\begin{array}{c}\text { IGFBP } \\
4\end{array}$ \\
\hline 4 & CCL24 & CCL26 & FGF-6 & FGF-7 & $\begin{array}{l}\text { Flt-3 } \\
\text { Ligand }\end{array}$ & $\begin{array}{c}\begin{array}{c}\text { Fractal } \\
\text { kine }\end{array} \\
\text { (a) }\end{array}$ & CXCL6 & GDNF & $\begin{array}{l}\text { GM- } \\
\text { CSF }\end{array}$ & 1-309 & IFN-Y & $\begin{array}{c}\text { IGFBP- } \\
1\end{array}$ & $\begin{array}{c}\text { IGFBP- } \\
2\end{array}$ & $\begin{array}{c}\text { - IGFBP } \\
4\end{array}$ \\
\hline 5 & IGF-I & IL-10 & IL-13 & IL-15 & IL-16 & IL-1 $\alpha$ & IL-1 $\beta$ & IL-1ra & CXCL5 & IL-3 & IL-4 & IL-5 & IL-6 & IL-7 \\
\hline 6 & IGF-I & IL-10 & $\mathrm{IL}-13$ & $\mathrm{IL}-15$ & IL-16 & IL-1 $\alpha$ & IL-1 $\beta$ & IL-1ra & CXCL5 & IL-3 & IL-4 & IL-5 & IL-6 & IL-7 \\
\hline 7 & Leptin & LIGHT & MCP-1 & MCP-2 & MCP-3 & MCP-4 & M-CSF & MDC & MIG & IIP-10 & CCL2O & NAP-2 & NT-3 & PAF \\
\hline 8 & Leptin & LIGHT & MCP-1 & -2 & D-3 & MCP-4 & M-CSF & MDC & MIG & MIP-1б & CCL2O & NAP-2 & NT-3 & PARC \\
\hline 9 & $\begin{array}{l}\text { PDGF- } \\
\text { BB }\end{array}$ & $\begin{array}{c}\text { RANTE } \\
\mathrm{S}\end{array}$ & SCF & SDF-1 & TARC & TGF- $\beta 1$ & TGF- $\beta 3$ & TNF- $\alpha$ & TNF- $\beta$ & NEG & NEG & NEG & NEG & POS \\
\hline & $\begin{array}{l}\text { PDGF- } \\
\text { BB }\end{array}$ & $\begin{array}{c}\text { RANTE } \\
\mathrm{S}\end{array}$ & SCF & SDF-1 & TARC & TGF- $\beta 1$ & TGF- $\beta 3$ & TNF- $\alpha$ & TNF $-\beta$ & NEG & NEG & NEG & NEG & POS \\
\hline
\end{tabular}

Figure 2. Cytokine synthesis induced by naringin. The synthesis of cytokines in cells was measured using the Quantibody ${ }^{\circledR}$ array. The red squares indicate the positive controls, whereas the blue squares indicate the negative controls. The spots were measured by densitometry. After subtracting the negative control and normalization with the positive control, the spots of stimulated MSC were compared with the corresponding spots of the unstimulated MSC. MSC, mesenchymal stromal cells. 

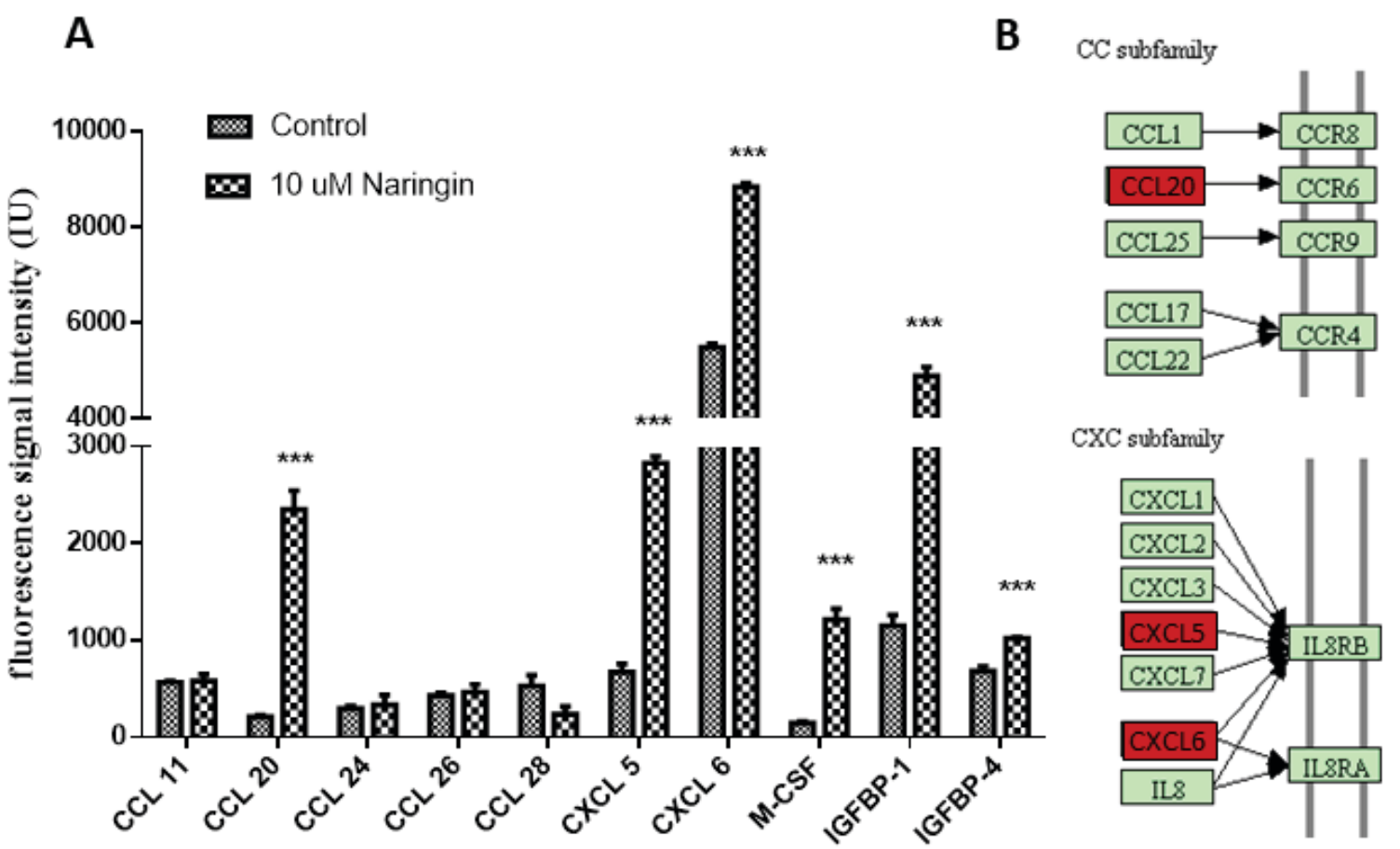

Figure 3. Cytokine-cytokine receptor interaction of cytokines synthesized by MSCs. (A) Following treatment with naringin, an increased cytokine synthesis of CXCL-6, CCL-20, M-CSF, IGFBP-1, IGFBP-4 and CXCL5 was observed. (B) Cytokine-cytokine receptor interaction between the synthesized cytokines. The differentially secreted cytokines are presented in their interaction pathway including IL-8RB, IL-8RA and CCR6 according to the cytokine-cytokine receptor interaction pathway $(04060 \mathrm{hsa})$ in the Kyoto Encyclopedia of Genes and Genomes database (red: significantly upregulated). ${ }^{* * *} \mathrm{P}<0.001$. CXCL, C-X-C motif chemokine; CCL, C-C motif chemokine; IL-8RB, C-X-C chemokine receptor type 2; IL-8RA, C-X-C chemokine receptor type 1; CCR, C-C chemokine receptor; IL8, interleukin-8; MSC, mesenchymal stromal cells.

\section{Results}

Effects of naringin on the migration of MSCs. A scratch assay was performed to investigate the effect of naringin on the migration of MSCs. The MSCs of all groups moved towards the blank area to a certain extent after $6 \mathrm{~h}$, indicating a certain level of migration ability. Compared with the control group, MSCs cultured with $10 \mu \mathrm{M}$ naringin significantly surpassed the baseline $(\mathrm{P}<0.05)$, indicating that the migration ability of MSCs increased with naringin stimulation (Fig. 1).

MSCs exhibit strong autocrine and paracrine functions (27) and, therefore, it was hypothesized that MSCs could alter the composition of the supernatant following treatment with naringin, making the supernatant a possible chemoattractant. The supernatant may have increased the migration of MSCs. Therefore, in another experiment, MSCs were pretreated with $10 \mu \mathrm{M}$ naringin. After $6 \mathrm{~h}$, the supernatant of the MSCs was extracted to culture a new batch of MSCs and a scratch assay was performed. An increased number of MSCs from the supernatant treatment crossed the baseline compared with the group of MSCs directly cultured with naringin $(\mathrm{P}<0.05)$. The above results indicated that treatment with the supernatant could significantly increase the migration ability of MSCs (Fig. 1). The present study also aimed to determine whether MSCs could synthesize factors that promote cellular migration following treatment with naringin. An antibody array experiment was subsequently conducted to identify these factors.

Effects of naringin on cellular chemokine synthesis by MSCs. To determine the influence of stimulation with naringin on

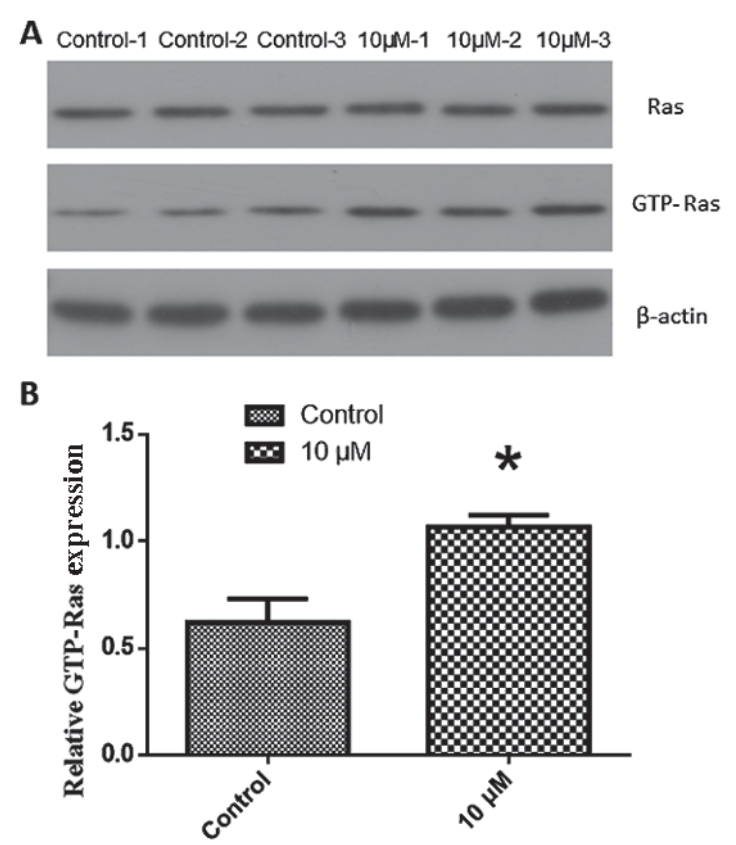

Figure 4. Naringin activates the Ras signaling pathway in MSCs. (A) Control 1-3 MSCs were maintained in the basal medium alone and $10 \mu \mathrm{M} 1-3$ cells were cultured with $10 \mu \mathrm{M}$ naringin. Experiments were performed in triplicate and repeated 3 times. (B) Quantitative results of western blot analysis of Ras activity following treatment with naringin $(10 \mu \mathrm{M}) .{ }^{*} \mathrm{P}<0.05$. GTP, guanosine-5'-triphosphate; MSC, mesenchymal stromal cells.

human MSCs at the protein level, Quantibody ${ }^{\circledR}$ arrays were performed. The treatment group was stimulated with $10 \mu \mathrm{M}$ 

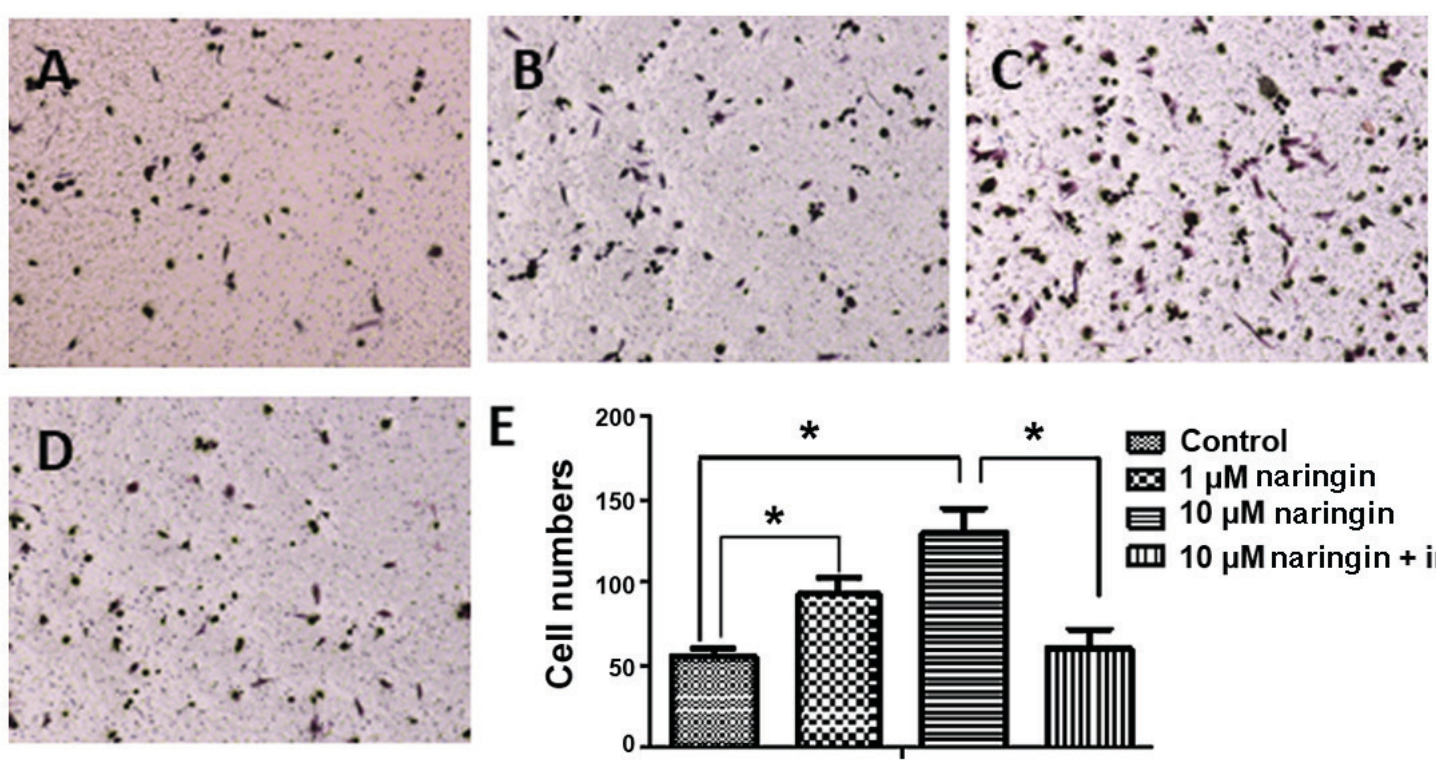

Figure 5. Activation Ras promotes MSC migration. Transwell migration assays were performed. MSCs were maintained in (A) the basal medium alone, (B) with $1 \mu \mathrm{M}$ naringin, (C) with $10 \mu \mathrm{M}$ naringin, or (D) with $10 \mu \mathrm{M}$ naringin and Ras inhibitor. (E) The results were quantitatively analyzed. membranes were observed under a light microscope (magnification, $\mathrm{x} 400$ ). Results were obtained from three independent experiments and expressed as the mean \pm standard deviation ( $\mathrm{n}=3$ in each experiment). ${ }^{*} \mathrm{P}<0.05$. MSC, mesenchymal stromal cells.

naringin and compared with the non-stimulated culture for 7 days (Figs. 2 and 3).

Statistical analysis demonstrated identification of seven cytokines that were differentially synthesized between the two groups. Following treatment with naringin, an increased cytokine synthesis (relative level, $>1.5$-fold change) of $\mathrm{C}-\mathrm{X}-\mathrm{C}$ motif chemokine (CXCL)6, C-C motif chemokine (CCL)20, macrophage colony-stimulating factor (M-CSF), insulin-like growth factor-binding protein (IGFBP)-1, IGFBP-4 and CXCL5 was observed (relative level, $>1.5$ fold change). Decreased cytokine synthesis (relative level, $<0.5$-fold change) was observed for CCL28 (Fig. 3A).

Based on the search criteria for differential secretion used in the present study, Statistical analysis resulted in identification of three cytokines (relative level, $>1.5$-fold control). Increased secretion of cytokines CXCL5, CXCL6 and CCL20 followed induction with naringin. The differentially secreted cytokines are presented in their interaction pathways, including IL-8RB, IL-8RA and CCR6 according to the cytokine-cytokine receptor interaction pathway (hsa04060; https://www.kegg. jp/kegg-bin/show_pathway?hsa04060+6364) in the Kyoto Encyclopedia of Genes and Genomes database (Fig. 3B).

Naringin induces MSCs to activate the Ras signaling pathway and enhance MSC migration. To verify the hypothesis that the Ras signaling pathway of MSCs could be activated by treatment with naringin, western blot analysis was performed. Compared with the control group, the expression of GTP-Ras in MSCs increased significantly following treatment with $10 \mu \mathrm{M}$ of naringin $(\mathrm{P}<0.05)$. These results indicated that naringin could activate the Ras signaling pathway in MSCs (Fig. 4).

To investigate whether activation of the Ras signaling pathway could increase the migration of MSCs, a Transwell migration assay was performed. Compared with the control group, the number of MSCs migrating towards the other side of the membrane increased significantly following treatment with 1 or $10 \mu \mathrm{M}$ naringin. However, following treatment with the Ras inhibitor, cell migration was significantly reduced compared with the group treated with $10 \mu \mathrm{M}$ naringin. This result suggested that activation and inhibition of the Ras signaling pathway significantly enhanced and suppressed the migration of MSCs, respectively (Fig. 5).

\section{Discussion}

In the first scratch assay, it was observed that the migration of MSCs treated with an appropriate concentration of naringin was enhanced compared with the control group, suggesting that naringin promoted the migration of MSCs. In another experiment, the supernatant of MSCs induced with naringin was used to culture a separate batch of MSCs. The migration of MSCs treated with the supernatant was enhanced compared with that of the MSCs of the control group and the group directly treated with an identical concentration of naringin. The above results suggested that the supernatant may contain certain cytokines that promote MSC migration. Therefore, it was hypothesized that, following treatment with naringin, MSCs may synthesize certain cytokines to further enhance their mobility. However, this hypothesis requires further verification, since the present experiment did not control for all the potentially confounding variables.

To confirm whether the synthesis of specific cytokines by MSCs was enhanced following treatment with naringin, and to identify the cytokines responsible for enhancing the mobility of MSCs, a Quantibody ${ }^{\circledR}$ array was performed. The results demonstrated that the synthesis of CXCL5, CXCL6 and CCL20 increased significantly. The CCL subfamily contains $>20$ members with two neighboring cysteine residues in the $\mathrm{N}$-terminal domain; these predominantly 
stimulate mononuclear cells and certain subpopulations of $\mathrm{T}$ cells (28). CCL20, also known as macrophage inflammatory protein-3, exerts its function by binding to its receptor, C-C chemokine receptor type 6 (29). CCL20 primarily stimulates dendritic cells and numerous types of immune cells, and may also regulate bone mass accrual (30). The characteristic molecular structure of the $\mathrm{C}-\mathrm{X}-\mathrm{C}$ motif subfamily consists of an amino acid between two cysteine residues at the $\mathrm{N}$-terminus (31). The C-X-C motif subfamily proteins are produced by activated mononuclear cells, endothelial cells, fibroblasts and megakaryocytes, and the majority of members can stimulate neutrophils, T cells and B cells (32-34). CXCL5, also known as epithelial-derived neutrophil-activating peptide 78 , is primarily produced by cells upon stimulation by interleukin-1 or tumor necrosis factor- $\alpha$ (35). Studies have shown that CXCL5 secretion affects differentiation and migration of MSCs (36). CXCL6, also known as granulocyte chemotactic protein 2 , exerts its stimulatory effect on white blood cells and promotes angiogenesis and antibacterial activity by interacting with chemokine receptors $\mathrm{C}-\mathrm{X}-\mathrm{C}$ chemokine receptor type (CXCR)1 and CXCR2 (37). CXCL6 also induces angiogenesis and promotes tumor growth (38). The above studies suggested that differentially secreted chemokines in naringin-induced MSCs may affect MSCs and other associated cell types, including immune cells, in the bone fracture microenvironment. Naringin may promote MSC migration by stimulating chemokine synthesis and secretion. Increased concentrations of chemokines in the bone fracture microenvironment may in turn promote the directional migration of MSCs and associated cells. Further experiments are required to elucidate the specific roles of individual chemokines during MSC migration. Subsequent studies should investigate the role of naringin in the promotion of MSC osteogenic differentiation.

The present study also aimed to identify the signaling pathways that regulate MSC migration using the Quantibody ${ }^{\circledR}$ assays. The differentially secreted cytokines (insulin-like growth factor-binding protein and M-CSF) were involved in the transmission of the Ras signaling pathway $(39,40)$. This indicated that the Ras signaling pathway may regulate stem cell migration. Therefore, the authors of the present study hypothesized that naringin may facilitate MSC migration by activating the Ras signaling pathway. To test this hypothesis, western blotting experiment were conducted to detect expression of relevant proteins in naringin-induced MSCs. The results indicated that following treatment with naringin GTP-Ras content in MSCs significantly increased. The expression level of GTP-Ras represents the activation of Ras (24) and, therefore, the results of the present study indicated that naringin can be considered a stimulator of the Ras signaling pathway in MSCs. In subsequent experiments, MSCs were treated with a Ras inhibitor and the Transwell assay revealed that MSC migration was significantly decreased compared with the group treated with $10 \mu \mathrm{M}$ naringin. The above results indicated that naringin activated the Ras signaling pathway, thereby promoting MSC migration.

In the present study, a preliminary analysis of the Quantibody ${ }^{\circledR}$ array results was performed, and these results require further verification. Several of the results merit further study. For example, CCL-5 also serves a role in the nuclear factor- $\kappa \mathrm{B}$ signaling pathway (41). It can be hypothesized that naringin may affect this signaling pathway. However, whether this signaling pathway is activated or inhibited requires experimental confirmation. The nuclear factor $-\kappa \mathrm{B}$ signaling pathway serves an important role in MSC differentiation into mature bone (42) and, therefore, its activity under the effects of naringin should be further investigated to advance the understanding of the molecular mechanism by which naringin affects MSCs.

\section{Acknowledgements}

Not applicable.

\section{Funding}

The present study was supported by a grant from the Hangzhou Medical and Health Science and Technology Plan Project (grant no. 2018B012) and Zhejiang Chinese Medical University Scientific Research Fund Project (grant no. 2018ZY26).

\section{Availability of data and materials}

The datasets used and/or analyzed during the current study are available from the corresponding author on reasonable request.

\section{Authors' contributions}

All authors have contributed significantly and are in agreement with the content of the manuscript. FL designed the experiments and wrote the manuscript. $\mathrm{GH}$ designed the experiments was a major contributor in writing the manuscript. YZ performed cell experiments and performed data analysis. All authors read and approved the final manuscript.

\section{Ethics approval and consent to participate}

Not applicable.

\section{Patient consent for publication}

Not applicable.

\section{Competing interests}

The authors declare that they have no competing interests.

\section{References}

1. Chtourou Y, Aouey B, Aroui S, Kebieche M and Fetoui H: Anti-apoptotic and anti-inflammatory effects of naringin on cisplatin-induced renal injury in the rat. Chem Biol Interact 243: $1-9,2016$

2. Yoshinaga A, Kajiya N, Oishi K, Kamada Y, Ikeda A, Chigwechokha PK, Kibe T, Kishida M, Kishida S, Komatsu M and Shiozaki K: NEU3 inhibitory effect of naringin suppresses cancer cell growth by attenuation of EGFR signaling through GM3 ganglioside accumulation. Eur J Pharmacol 782: 21-29, 2016.

3. Kandhare AD, Ghosh P and Bodhankar SL: Naringin, a flavanone glycoside, promotes angiogenesis and inhibits endothelial apoptosis through modulation of inflammatory and growth factor expression in diabetic foot ulcer in rats. Chem Biol Interact 219: 101-112, 2014. 
4. Ikemura M, Sasaki Y, Giddings JC and Yamamoto J: Preventive effects of hesperidin, glucosyl hesperidin and naringin on hypertension and cerebral thrombosis in stroke-prone spontaneously hypertensive rats. Phytother Res 26: 1272-1277, 2012.

5. Xiao Y, Li LL, Wang YY, Guo JJ, Xu WP, Wang YY and Wang Y: Naringin administration inhibits platelet aggregation and release by reducing blood cholesterol levels and the cytosolic free calcium concentration in hyperlipidemic rabbits. Exp Ther Med 8: 968-972, 2014.

6. Mao Z, Gan C, Zhu J, Ma N, Wu L, Wang L and Wang X: Anti-atherosclerotic activities of flavonoids from the flowers of Helichrysum arenarium L. MOENCH through the pathway of anti-inflammation. Bioorg Med Chem Lett 27: 2812-2817, 2017.

7. Zamanian M, Hajizadeh M, Shamsizadeh A, Moemenzadeh M, Amirteimouri M, Elshiekh M and Allahtavakoli M: Effects of naringin on physical fatigue and serum MMP-9 concentration in female rats. Pharm Biol 55: 423-427, 2017.

8. Wang S, Bao YR, Li TJ, Yu T, Chang X, Yang GL and Meng XS: Mechanism of fructus aurantii flavonoids promoting gastrointestinal motility: From organic and inorganic endogenous substances combination point of view. Pharmacogn Mag 13: 372-377, 2017.

9. GuoD, Wang J,Wang X,LuoH,Zhang H, CaoD and Chen L: Double directional adjusting estrogenic effect of naringin from Rhizoma drynariae (Gusuibu). J Ethnopharmacol 138: 451-457, 2011

10. Toth PP, Patti AM, Nikolic D, Giglio RV, Castellino G, Biancucci T, Geraci F, David S, Montalto G, Rizvi A and Rizzo M: Bergamot reduces plasma lipids, atherogenic smal dense LDL and subclinical atherosclerosis in subjects with moderate hypercholesterolemia: A 6 months prospective study. Front Pharmacol 6: 299, 2016.

11. Baskaran G, Salvamani S, Ahmad SA, Shaharuddin NA, Pattiram PD and Shukor MY: HMG-CoA reductase inhibitory activity and phytocomponent investigation of Basella alba leaf extract as a treatment for hypercholesterolemia. Drug Des Devel Ther 9: 509-517, 2015.

12. Nyane NA, Tlaila TB, Malefane TG, Ndwandwe DE and Owira PMO: Metformin-like antidiabetic, cardio-protective and non-glycemic effects of naringenin: Molecular and pharmacological insights. Eur J Pharmacol 803: 103-111, 2017.

13. Song N, Zhao Z, Ma X, Sun X, Ma J, Li F, Sun L and Lv J: Naringin promotes fracture healing through stimulation of angiogenesis by regulating the VEGF/VEGFR-2 signaling pathway in osteoporotic rats. Chem Biol Interact 261: 11-17, 2017.

14. Fan J, Li J and Fan Q: Naringin promotes differentiation of bone marrow stem cells into osteoblasts by upregulating the expression levels of microRNA-20a and downregulating the expression levels of PPAR $\gamma$. Mol Med Rep 12: 4759-4765, 2015.

15. Li N, Jiang Y, Wooley PH, Xu Z and Yang SY: Naringin promotes osteoblast differentiation and effectively reverses ovariectomy-associated osteoporosis. J Orthop Sci 18: 478-485, 2013.

16. Lin F, Xue D, Xie T and Pan Z: HMGB1 promotes cellular chemokine synthesis and potentiates mesenchymal stromal cel migration via Rap1 activation. Mol Med Rep 14: 1283-1289, 2016.

17. Lin F, Zhang W, Xue D, Zhu T, Li J, Chen E, Yao X and Pan Z: Signaling pathways involved in the effects of HMGB1 on mesenchymal stem cell migration and osteoblastic differentiation. Int J Mol Med 37: 789-797, 2016.

18. Feng L, Xue D, Chen E, Zhang W, Gao X, Yu J, Feng Y and Pan Z: HMGB1 promotes the secretion of multiple cytokines and potentiates the osteogenic differentiation of mesenchymal stem cells through the Ras/MAPK signaling pathway. Exp Ther Med 12: 3941-3947, 2016

19. Zhang H, Kot A, Lay YE, Fierro FA, Chen H, Lane NE and Yao W: Acceleration of fracture healing by overexpression of basic fibroblast growth factor in the mesenchymal stromal cells. Stem Cells Transl Med 6: 1880-1893, 2017.

20. Li X, He L, Yue Q, Lu J, Kang N, Xu X, Wang H and Zhang H: MiR-9-5p promotes MSC migration by activating $\beta$-catenin signaling pathway. Am J Physiol Cell Physiol 313: C80-C93, 2017.

21. Luan XY, Zhang GB, Hu YM, Yu GH, Wang MY, Duan QY, Duan X and Zhang XG: Effects of MSC on cell cycle, phenotype and cytokine secretion of T cells activated by PHA. Xi Bao Yu Fen Zi Mian Yi Xue Za Zhi 23: 402-405, 2007 (In Chinese).

22. Rocks O, Peyker A and Bastiaens PI: Spatio-temporal segregation of Ras signals: One ship, three anchors, many harbors. Curr Opin Cell Biol 18: 351-357, 2006.

23. Thatcher JD: The Ras-MAPK signal transduction pathway. Sci Signal 3: tr1, 2010.

24. Khosravi-Far R and Der CJ: The Ras signal transduction pathway. Cancer Metastasis Rev 13: 67-89, 1994.
25. Zhou J, Zhang S, Chen X, Zheng X, Yao Y, Lu G and Zhou J: Palbociclib, a selective CDK4/6 inhibitor, enhances the effect of selumetinib in RAS-driven non-small cell lung cancer. Cancer Lett 408: 130-137, 2017

26. Li X, Li D, Wikstrom JD, Pivarcsi A, Sonkoly E, Ståhle M and Landén NX: MicroRNA-132 promotes fibroblast migration via regulating RAS p21 protein activator 1 in skin wound healing. Sci Rep 7: 7797, 2017.

27. Gao D, Xie J, Zhang J, Feng C, Yao B, Ma K, Li J, Wu X, Huang S and $\mathrm{Fu} X$ : MSC attenuate diabetes-induced functional impairment in adipocytes via secretion of insulin-like growth factor-1. Biochem Biophys Res Commun 452: 99-105, 2014.

28. Van Coillie E, VanDamme J and Opdenakker G: The $\mathrm{MCP} /$ eotaxin subfamily of $\mathrm{CC}$ chemokines. Cytokine Growth Factor Rev 10: 61-86, 1999.

29. Baba M, Imai T, Nishimura M, Kakizaki M, Takagi S, Hieshima K, Nomiyama H and Yoshie O: Identification of CCR6, the specific receptor for a novel lymphocyte-directed CC chemokine LARC. J Biol Chem 272: 14893-14898, 1997.

30. Doucet M, Jayaraman S, Swenson E, Tusing B, Weber KL and Kominsky SL: CCL20/CCR6 signaling regulates bone mass accrual in mice. J Bone Miner Res 31: 1381-1390, 2016.

31. Hieshima K, Imai T, Opdenakker G, Van Damme J, Kusuda J, Tei H, Sakaki Y, Takatsuki K, Miura R, Yoshie O and Nomiyama H: Molecular cloning of a novel human CC chemokine liver and activation-regulated chemokine (LARC) expressed in liver. Chemotactic activity for lymphocytes and gene localization on chromosome 2. J Biol Chem 272: 5846-5853, 1997.

32. Kim GW, Han MS, Park HR, Lee EJ, Jung YK, Usmani SE, Ulici V, Han SW and Beier F: CXC chemokine ligand 12a enhances chondrocyte proliferation and maturation during endochondral bone formation. Osteoarthritis Cartilage 23: 966-974, 2015.

33. Le Y, Zhou Y, Iribarren P and Wang J: Chemokines and chemokine receptors: Their manifold roles in homeostasis and disease. Cell Mol Immunol 1: 95-104, 2004.

34. Graham GJ and Locati M: Regulation of the immune and inflammatory responses by the 'atypical' chemokine receptor D6. J Pathol 229: 168-175, 2013

35. Chang MS, McNinch J, Basu R and Simonet S: Cloning and characterization of the human neutrophil-activating peptide (ENA-78) gene. J Biol Chem 269: 25277-25282, 1994

36. Nedeau AE, Bauer RJ, Gallagher K, Chen H, Liu ZJ and Velazquez OC: A CXCL5- and bFGF-dependent effect of PDGF-B-activated fibroblasts in promoting trafficking and differentiation of bone marrow-derived mesenchymal stem cells. Exp Cell Res 314: 2176-2186, 2008.

37. Catusse J, Struyf S, Wuyts A, Weyler M, Loos T, Gijsbers K, Gouwy M, Proost P and Van Damme J: Rabbit neutrophil chemotactic protein (NCP) activates both CXCR1 and CXCR2 and is the functional homologue for human CXCL6. Biochem Pharmacol 68: 1947-1955, 2004.

38. Verbeke H, Struyf S, Berghmans N, Van Coillie E, Opdenakker G, Uyttenhove C, Van Snick J and Van Damme J: Isotypic neutralizing antibodies against mouse GCP-2/CXCL6 inhibit melanoma growth and metastasis. Cancer Lett 302: 54-62, 2011.

39. Kuemmerle JF and Zhou H: Insulin-like growth factor-binding protein-5 (IGFBP-5) stimulates growth and IGF-I secretion in human intestinal smooth muscle by Ras-dependent activation of p38 MAP kinase and Erk1/2 pathways. J Biol Chem 277: 20563-20571, 2002.

40. Bradley EW, Ruan MM, Vrable A and Oursler MJ: Pathway crosstalk between Ras/Raf and PI3K in promotion of M-CSF-induced MEK/ERK-mediated osteoclast survival. J Cell Biochem 104: 1439-1451, 2008

41. Pham TH, Kim MS, Le MQ, Song YS, Bak Y, Ryu HW, Oh SR and Yoon DY: Fargesin exerts anti-inflammatory effects in THP-1 monocytes by suppressing PKC-dependent AP-1 and NF-kB signaling. Phytomedicine 24: 96-103, 2017.

42. Wang YJ, Zhang HQ, Han HL, Zou YY, Gao QL and Yang GT: Taxifolin enhances osteogenic differentiation of human bone marrow mesenchymal stem cells partially via NF- $\mathrm{B}$ pathway. Biochem Biophys Res Commun 490: 36-43, 2017.

This work is licensed under a Creative Commons Attribution-NonCommercial-NoDerivatives 4.0 International (CC BY-NC-ND 4.0) License. 